PERMANA : Jurnal Perpajakan, Manajemen, dan Akuntansi Analisis Perbandingan Penggunaan Forward Contract....

\title{
Analisis Perbandingan Penggunaan Forward Contract Hedging dan Money Market Hedging dengan Open Position dalam Meminimalkan Pembayaran Hutang Impor
}

(Studi Kasus pada Perusahaan Sektor Infrastruktur, Utilitas dan Transportasi yang Terdaftar di BEI Periode 2014-2018)

Manajemen Keuangan

\author{
Siti Subaedah ${ }^{1)}$, Tri Sulistyani ${ }^{2)}$, Amirah $^{3)}$
}

Fakultas Ekonomi dan Bisnis, Universitas Pancasakti, Tegal szubaedah7@gmail.com, sulistyani.tri@gmail.com, amier4h@gmail.com

\begin{abstract}
The purpose of this study are: 1) To find out whether or not there is a difference between the use of forward contract hedging and open position in minimizing payment of import debt. 2) To find out whether or not there is a difference between the use of money market hedging and open positions in minimizing payment of import debt. The data collected in this study is quantitative data. Sources of data in this study are secondary sources obtained from annual financial reports published from the Indonesia Stock Exchange in the 2014-2018 period. While the method of data analysis and hypothesis testing used is a different T-test or independent sample T-test. Based on the research results obtained: 1) There is no significant difference between the use of forward contract hedging and open positions in minimizing payment of import debt. 2) There is no significant difference between the use of money market hedging and open positions in minimizing the payment of import debt. However, between the two hedging techniques, the lowest amount of import debt is when companies use the money market hedging technique.
\end{abstract}

Keywords: Forward Contract Hedging, Money Market Hedging, Open Position, Import Debt Amount

\begin{abstract}
Abstrak
Tujuan Penelitian ini adalah : 1) Untuk mengetahui ada atau tidaknya perbedaan antara penggunaan forward contract hedging dengan open position dalam meminimalkan pembayaran hutang impor. 2) Untuk mengetahui ada atau tidaknya perbedaan antara penggunaan money market hedging dengan open position dalam meminimalkan pembayaran hutang impor. Data yang dikumpulkan dalam penelitian ini adalah data kuantitatif. Sumber data dalam penelitian ini adalah sumber sekunder yang diperoleh dari laporan keuangan tahunan yang dipublikasikan dari Bursa Efek Indonesia periode 2014-2018. Sedangkan metode analisis data dan uji hipotesis yang digunakan adalah dengan uji beda T-test atau uji independent sampel T-test. Berdasarkan hasil penelitian diperoleh : 1) Tidak ada perbedaan yang signifikan antara penggunaan forward contract hedging dengan open position dalam meminimalkan pembayaran hutang impor. 2) Tidak ada perbedaan yang signifikan antara penggunaan money market hedging dengan open position dalam meminimalkan pembayaran hutang impor. Namun, di antara kedua teknik hedging tersebut, jumlah hutang impor yang paling rendah adalah ketika perusahaan menggunakan teknik money market hedging.
\end{abstract}

Kata kunci : Forward Contract Hedging, Money Market Hedging, Open Position, Jumlah Hutang Impor 


\section{PENDAHULUAN}

1.1 Latar Belakang

Perdagangan internasional yang dilakukan perusahaan Multinasional (Multinational corporation-MNC) terdapat kegiatan ekspor impor antar perusahaan luar negeri dan berhubungan langsung dengan kurs valuta asing, maka perusahaan harus mampu meramalkan naik turunnya kurs mata uang yang digunakan dalam transaksi tersebut (Misalkan dalam US\$), karena perubahan kurs valuta asing sangat berpengaruh dalam kegiatan operasional perusahaan khususnya pada cash flow perusahan. Apabila terjadi perubahan nilai tukar valuta asing, perusahaan akan mengalami kerugian atau keuntungan akibat perubahan tersebut.

Nilai mata uang setiap negara yang selalu berubah satu sama lainnya menyebabkan ketidakpastian bagi perusahaan yang terlibat dalam perdagangan internasional terlebih lagi di Indonesia menerapkan sistem kurs mengambang yang artinya tidak adanya peran pemerintah dalam menekan perubahan nilai kurs. Untuk mengantisipasi ketidakpastian tersebut maka perusahaan harus melindungi aktiva atau kewajibannya agar nilainya dapat diprediksi.

Jumlah utang luar negeri sangat besar khususnya utang yang dimiliki oleh perusahaan sektor non keuangan dapat berpotensi memiliki risiko ketidaksesuaian nilai tukar, yang disebut dengan risiko currency mismatch, sebagai akibat dari fluktuasi pergerakan nilai tukar khususnya pengaruh dari depresiasi nilai tukar. Untuk mengantisipasi potensi risiko nilai tukar (currency mismatch) sebagai akibat dari depresiasi nilai tukar dan untuk meminimalisir risiko valas dalam hutang impor, perusahaan dituntut untuk melakukan lindung nilai (hedging) terhadap utang luar negeri agar dapat melindungi kondisi keuangan perusahaan dari kebangkrutan.

Prinsip hedging adalah menutupi kerugian posisi aset awal dengan keuntungan dari posisi instrumen hedging. Menurut Hady (2016:179) Setiap perusahaan yang akan melakukan hedging terhadap seluruh atau sebagian dari transaksi international cash flow dapat memilih alternatif dari beberapa teknik hedging sesuai dengan kepentingan perusahaan diantaranya adalah money market hedging, forward contract hedging, future contract hedging dan currency option hedging. Namun, masih banyak juga perusahaan yang mempunyai hutang impor dapat melakukan open position. Metode open position ini merupakan metode dengan membiarkan terjadinya fluktuasi kurs terhadap nilai tukar mata uang asing sesuai dengan keadaan pasar yang ada.

Ratih (2013), Mitariani (2013), Suidarma (2016), dan Mustafidah (2017) melakukan penelitian dengan membandingkan penggunaan teknik-teknik hedging dan diperoleh hasil penelitian yang berbeda-beda. Ada yang menemukan hasil bahwa tidak ada perbedaan nilai hutang impor perusahaan menggunakan hedging dengan open position namun lebih efisien dengan menggunakan hedging dan ada pula yang menemukan hasil bahwa ada perbedaan nilai hutang impor perusahaan menggunakan hedging dengan open position.

Perusahaan yang menjadi objek penelitian adalah pada perusahaan Sektor Infrastruktur, Utilitas dan Transportasi yang terdaftar di BEI tahun 2014-2018, hal ini dikarenakan perusahaan di Sektor tersebut cukup banyak yang melakukan transaksi internasional dengan menggunakan mata uang asing sehingga memiliki risiko valuta asing, memiliki sejumlah hutang impor berupa valuta asing yaitu US Dollar Amerika dalam jumlah yang besar dan melihat dari perusahaan sektor tersebut sudah cukup banyak yang melakukan hedging (lindung nilai). Dengan membandingkan teknik hedging yang terdiri dari teknik forward contract hedging dan money market hedging dengan open position, diharapkan dapat mengetahui teknik mana yang lebih efisien digunakan dalam meminimalkan pembayaran hutang impor.

1.2 Rumusan Masalah

Berdasarkan latar belakang yang telah diuraikan sebelumnya, maka dapat ditetapkan beberapa rumusan masalah sebagai berikut :

a. Apakah ada perbedaan antara penggunaan forward contract hedging dengan open position dalam meminimalkan pembayaran hutang impor?

b. Apakah ada perbedaan antara penggunaan money market hedging dengan open position dalam meminimalkan pembayaran hutang impor?

\subsection{Tujuan Penelitian}

Berdasarkan rumusan masalah yang telah disebutkan, maka tujuan dari penelitian ini adalah sebagai berikut :

a. Untuk mengetahui ada atau tidaknya perbedaan antara penggunaan forward contract hedging dengan open position dalam meminimalkan pembayaran hutang impor. 
b. Untuk mengetahui ada atau tidaknya perbedaan antara penggunaan money market hedging dengan open position dalam meminimalkan pembayaran hutang impor.

\section{Kerangka Pemikiran Dan Hipotesis}

\subsection{Kerangka Pemikiran}

Untuk menghadapi risiko fluktuasi kurs valas pada nilai hutang impor tersebut, perusahaan dapat mengambil dua cara, yakni dengan bersikap open position terhadap spot rate masa depan di mana nilai hutang impor perusahaan di masa mendatang tergantung dengan besarnya spot rate masa depan saat hutang jatuh tempo atau dengan melakukan lindung nilai hutang impor. Dalam penelitian ini menjelaskan bahwa untuk mengetahui hutang suatu perusahaan dengan menggunakan 2 macam teknik analisa hedging yaitu forward contract hedging dan money market hedging. Untuk mengetahui cara mana yang lebih efisien digunakan dalam pembayaran hutang impor di masa datang, maka perlu dilakukan perbandingan antara open position dan teknik hedging. Berdasarkan uraian tersebut, maka dapat digambarkan suatu kerangka pemikiran sebagai berikut :

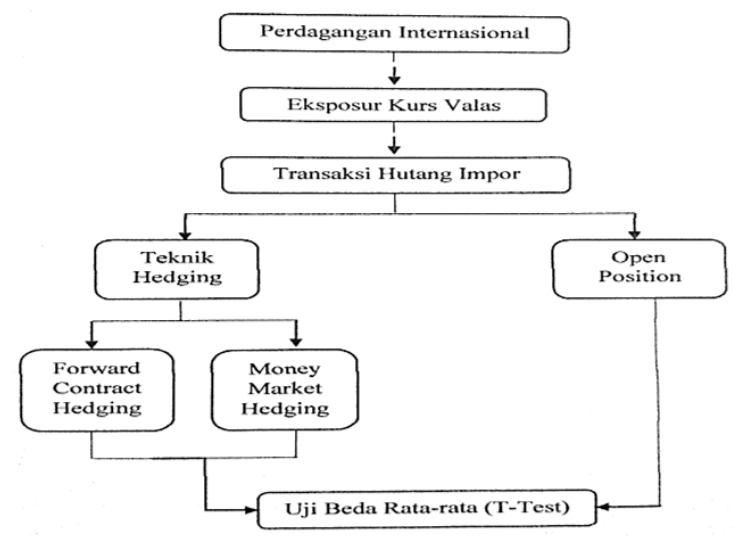

Gambar 1

Kerangka Pemikiran

\subsection{Hipotesis}

Hipotesis merupakan jawaban sementara atas rumusan masalah yang diajukan. Hipotesis dalam penelitian ini adalah :

H1 : Ada perbedaan antara pembayaran hutang impor menggunakan forward contract hedging dengan pembayaran hutang impor menggunakan open position.

$\mathrm{H} 2$ : Ada perbedaan antara pembayaran hutang impor menggunakan money market hedging dengan pembayaran hutang impor menggunakan open position.

\section{Metode Penelitian}

Penelitian ini menggunakan jenis penelitian kuantitatif. Metode penelitian yang digunakan dalam penelitian ini adalah metode deskriptif komparatif. Metode deskriptif adalah metode yang digunakan dalam penelitian yang dilakukan untuk mengetahui nilai variabel mandiri, baik satu variabel atau lebih (independen) tanpa membuat perbandingan, atau menghubungkan dengan variabel lain. Metode komparatif merupakan suatu penelitian yang bersifat membandingkan keberadaan suatu variabel pada dua sampel atau lebih (Sugiyono, 2017: 20). Dalam penelitian ini membandingkan dua fenomena atau lebih ditinjau dari perbedaannya dan mengenali aspek-aspek tertentu yang lebih spesifik untuk mendapatkan data sekunder yang akan diolah, dianalisis dan dibandingkan dengan teori yang telah dipelajari.

3.1 Populasi dan Sampel

a. Populasi

Populasi adalah wilayah generalisasi yang terdiri atas obyek/subyek yang mempunyai kuantitas dan karakteristik tertentu yang ditetapkan oleh peneliti untuk dipelajari dan kemudian ditarik kesimpulannya (Sugiyono, 2017:136). Populasi yang diteliti dalam penelitian ini adalah seluruh perusahaan sektor infrastruktur, utilitas dan transportasi yang melakukan transaksi internasional berupa hutang impor dan terdaftar di Bursa Efek Indonesia selama periode penelitian tahun 2014-2018.

b. Sampel

Pemilihan sampel dalam penelitian ini dilakukan dengan menggunakan teknik non random sampling dengan metode purposive sampling. Purposive sampling adalah teknik penentuan sampel dengan pertimbangan tertentu (Sugiyono, 2017:144). Dimana pertimbangan tersebut berupa populasi yang memiliki kriteria berikut :

1) Perusahaan yang bergerak di sektor infrastruktur, utilitas dan transportasi yang terdaftar di Bursa Efek Indonesia periode 2014-2018.

2) Menerbitkan laporan keuangan yang telah diaudit per 31 Desember untuk 
periode 2014-2018.

3) Perusahaan yang melakukan transaksi keuangan internasional yang memiliki transaksi nilai hutang usaha USD dalam pembelian bahan baku selama periode 2014-2018 berturut-turut.

4) Perusahaan yang melakukan hedging dalam meminimalkan risiko perusahaan selama periode 20142018.

Berdasarkan kriteria yang disebutkan, maka terpilihlah 11 perusahaan sektor infrastruktur, utilitas dan transportasi yang memenuhi kriteria sebagai sampel dalam penelitian ini.

\subsection{Definisi Konseptual Dan Operasional Variabel}

Menurut Suliyanto (2018:147) variabel konseptual merupakan kumpulan konsep dari fenomena yang diteliti sehingga maknanya masih sangat abstrak dan dapat dimaknai secara subjektif dan dapat menimbulkan ambigu. Sedangkan definisi operasional variabel penelitian adalah suatu definisi mengenai variabel yang dirumuskan berdasarkan karakteristik-karakteristik variabel tersebut yang dapat diamati. Variabel penelitian adalah segala sesuatu yang berbentuk apa saja yang ditetapkan oleh peneliti untuk dipelajari sehingga diperoleh informasi tentang hal tersebut, kemudian ditarik kesimpulannya (Sugiyono, 2017:66). Yang menjadi variabel dalam penelitian ini adalah Forward Contract Hedging $\left(\mathrm{X}_{1}\right)$, Money Market Hedging $\left(\mathrm{X}_{2}\right)$ dan Open Position $\left(\mathrm{X}_{3}\right)$ dan dijelaskan sebagai berikut :

Tabel 1

\section{Operasional Variabel}

\begin{tabular}{|c|c|c|c|c|c|}
\hline No & Variabel & Definisi Operasional & Indikator & Ukuran & Skala \\
\hline 1. & $\begin{array}{l}\text { Forward Contract } \\
\text { Hedging } \\
\left(\mathrm{X}_{1}\right)\end{array}$ & $\begin{array}{l}\text { Suatu tindakan untuk } \\
\text { meminimalkan risiko } \\
\text { fluktuasi kurs valas dengan } \\
\text { forward rate, yakni kurs yang } \\
\text { ditentukan saat ini dan akan } \\
\text { diberlakukan di masa } \\
\text { mendatang }\end{array}$ & $\begin{array}{l}\text { Forward Rate } \times \text { Nilai } \\
\text { transaksi impor }\end{array}$ & $\mathrm{Rp}$ & Rasio \\
\hline 2. & $\begin{array}{l}\text { Money Market } \\
\text { Hedging } \\
\left(\mathrm{X}_{2}\right)\end{array}$ & $\begin{array}{l}\text { Suatu tindakan untuk } \\
\text { meminimalkan risiko } \\
\text { fluktuasi kurs valas dengan } \\
\text { meminjam dan } \\
\text { meminjamkan dua mata } \\
\text { uang yang berbeda }\end{array}$ & $\begin{array}{l}\text { Pinjaman }(\mathrm{Rp}) \times(1+\text { suku } \\
\text { bunga pinjaman } \times 30 / 360)\end{array}$ & $\mathrm{Rp}$ & Rasio \\
\hline 3. & $\begin{array}{l}\text { Open Position } \\
\left(\mathrm{X}_{3}\right)\end{array}$ & $\begin{array}{l}\text { Suatu tindakan dimana } \\
\text { nilai hutang tidak } \\
\text { menggunakan teknik } \\
\text { hedging, namun ditentukan } \\
\text { oleh besarnya kurs valas }\end{array}$ & $\begin{array}{l}\text { Future spot rate } \times \text { Nilai } \\
\text { transaksi impor }\end{array}$ & $\mathrm{Rp}$ & Rasio \\
\hline
\end{tabular}

\subsection{Teknik Pengumpulan Data}

Data yang dikumpulkan dalam penelitian ini adalah data sekunder. Data sekunder tersebut berupa laporan keuangan dan tahunan yang tercatat pada Bursa Efek Indonesia (BEI) pada periode 2014-2018 yang diperoleh dari situs resmi Bursa Efek Indonesia di http://www.idx.co.id dan data yang berkaitan dengan perubahan kurs Rupiah terhadap USD selama periode penelitian, suku bunga deposito dan suku bunga pinjaman diperoleh melalui http://www.bi.go.id.

\subsection{Metode Analisis Data}

Analisis perhitungan pembayaran hutang impor menggunakan teknik Hedging :

a. $\quad$ Pembayaran hutang impor menggunakan Forward Contract Hedging

$\mathrm{FR}=$ Spot rate $+($ Interest rate differential $\times$ spot rate $\times$ days $)$

$$
360 \times 100
$$

b. Pembayaran hutang impor menggunakan Money Market Hedging

1) Menentukan nilai Dollar pada saat hutang jatuh tempo

2) Mencari nilai sekarang (Present Value) dari hutang tersebut : 
Nilai hutang impor $=$ Forward rate $\times$ Nilai transaksi

Mengkonversikan nilai sekarang dari nilai hutang dollar tersebut ke dalam rupiah, lalu meminjam rupiah sebesar nilai sekarang dari nilai hutang tersebut untuk diinvestasikan ke dalam Dollar agar dapat menutupi nilai hutang saat jatuh tempo.

Pinjam an $\mathrm{Rp}=\mathrm{N}$ ilai sekarang dari hutang $\times$ spot $\mathrm{r}$ ate

3) Membayar pinjaman ditambah dengan bunga pada saat jatuh tempo. Jumlah nilai hutang yang harus dibayar pada saat jatuh tempo.

Pinjaman Rp $\times(1+$ suku bunga pinjaman/12)

c. Analisis perhitungan pembayaran hutang impor menggunakan Open Position Nilai hutang impor :

\section{Future spot rate $\times$ Nilai transaksi}

Metode analisis data yang digunakan untuk menguji hipotesis dalam penelitian ini adalah menggunakan analisis uji beda dua ratarata (t-test). Teknik analisis uji beda T-test digunakan untuk melihat ada atau tidaknya perbedaan pembayaran hutang impor perusahaan ketika menggunakan teknik hedging dengan open position.

\section{Hasil}

Uji beda statistik yang digunakan untuk membandingkan perbedaan rata-rata nilai hutang impor perusahaan ketika melakukan open position dengan menggunakan teknik forward contract hedging dan teknik money market hedging adalah menggunakan alat uji statistik dengan uji Independent Sampel T-Test. Berikut ini adalah hasil uji yang diperoleh :

\subsection{Perbedaan Forward Contract Hedging} dengan Open Position

Tabel 2

\section{Group Statistics}

\begin{tabular}{|c|c|c|c|c|c|}
\hline & $\begin{array}{l}\text { Teknik } \\
\text { Hedging }\end{array}$ & $\mathrm{N}$ & Mean & $\begin{array}{c}\text { Std. } \\
\text { Deviation }\end{array}$ & $\begin{array}{c}\text { Std. } \\
\text { Error } \\
\text { Mean }\end{array}$ \\
\hline \multirow{6}{*}{$\begin{array}{l}\text { Jumlah } \\
\text { Hutang }\end{array}$} & Forward & \multirow[t]{3}{*}{55} & 8201 & 122193762 & 1647660 \\
\hline & Contract & & 0577 & 6469,0073 & 35940,81 \\
\hline & Hedging & & $\begin{array}{l}7527, \\
0297\end{array}$ & 0 & 305 \\
\hline & Open & \multirow[t]{3}{*}{55} & 8236 & 122475865 & 1651464 \\
\hline & \multirow{2}{*}{ Position } & & 8173 & 8801,0957 & 23862,87 \\
\hline & & & $\begin{array}{r}7801, \\
2725\end{array}$ & 0 & 274 \\
\hline
\end{tabular}

$$
P V=\frac{\text { Nilai hutang }(\mathrm{US} \$)}{1+(\text { suku bunga deposito } / 12)}
$$

Sumber : SPSS 25, Data Diolah 2019

Tabel di atas menunjukkan bahwa Mean atau nilai hutang rata-rata yang menggunakan teknik forward contract hedging menunjukkan sebesar 820.105.777.527,0297 sedangkan dengan menggunakan open position sebesar 823.681.737.801,2725. Hal ini berarti nilai hutang yang menggunakan open position akan lebih besar dibandingkan yang menggunakan teknik forward contract hedging.

Berdasarkan uji beda statistik dari perbandingan rata-rata nilai hutang impor menggunakan teknik forward contract hedging dengan open position menunjukkan Sig. (2tailed) 0,988 . Hal ini berarti tidak ada perbedaan rata-rata nilai hutang impor ketika menggunakan teknik forward contract hedging dan metode open position, karena nilai signifikansi $(0,05)$ lebih kecil daripada nilai Sig. (2-tailed). Hal ini dapat disebabkan karena peningkatan nilai tukar Dolar AS terhadap Rupiah selama jatuh tempo setiap transaksi tidak signifikan, selain itu selisih suku bunga deposito Dolar AS dengan suku bunga deposito Rupiah terlalu tinggi. Nurmalasari (2013), Suidarma (2016) dan Mustafidah (2017) mendapatkan hasil penelitian yang sama, perbedaannya terletak di hasil signifikansinya dan penghematan penggunaan forward contract hedgingnya.

Sedangkan berdasarkan nilai hutang impor yang dihasilkan dari penggunaan teknik forward contract hedging pada 8 perusahaan menunjukkan nilai yang lebih rendah dibandingkan menggunakan metode open position. Berikut nilai hutang impor perusahaan :

Tabel 3

Nilai Hutang Impor Forward Contract Hedging dan Open Position

\begin{tabular}{|l|l|}
\hline \multicolumn{1}{|c|}{ Keterangan } & \multicolumn{1}{c|}{ Jumlah } \\
\hline Forward Contract & $\mathrm{Rp}$ \\
Hedging & $45.105 .817 .763 .986,60$ \\
\hline \multirow{2}{*}{ Open Position } & $\mathrm{Rp}$ \\
& $45.302 .495 .579 .070,00$ \\
\hline \multirow{2}{*}{ Selisih } & $\mathrm{Rp}$ \\
& $196.677 .815 .083,35$ \\
\hline
\end{tabular}

Sumber : Data Diolah, 2019

Dari perbandingan tabel di atas dapat dilihat bahwa terdapat selisih nilai hutang yang harus dibayarkan oleh perusahaan dari tahun 2014-2018 ketika menggunakan teknik forward contract hedging dan open position. Saat 
menggunakan teknik forward contract hedging perusahaan akan membayar sebesar Rp. 45.105.817.763.986,60 sedangkan saat tidak melakukan teknik hedging atau menggunakan metode open position sebesar $\mathrm{Rp}$. 45.302.495.579.070,00. Itu berarti penggunaan forward contract hedging akan memperoleh penghematan sebesar Rp. 196.677.815.083,35 meskipun menurut uji beda T-test tidak terdapat perbedaan yang signifikan.

4.2 Perbedaan Money Market Hedging dengan Open Position

Tabel 4

Hasil Uji Perbedaan Money Market Hedging dengan Open Position

Group Statistics

\begin{tabular}{|ll|r|r|r|r|}
\hline & $\begin{array}{l}\text { Teknik } \\
\text { Hedging }\end{array}$ & $\mathrm{N}$ & Mean & $\begin{array}{c}\text { Std. } \\
\text { Deviation }\end{array}$ & $\begin{array}{c}\text { Std. } \\
\text { Error } \\
\text { Mean }\end{array}$ \\
\hline \begin{tabular}{ll|r|r|} 
Jumlah \\
Hutang
\end{tabular} & Money & 55 & 8095 & 120427233 & 1623840 \\
& Market & & 8130 & 7263,0780 & 48830,21 \\
& Hedging & & 9442, & 0 & 085 \\
& & & 4061 & & \\
& Open & 55 & 8236 & 122475865 & 1651464 \\
& Position & & 8173 & 8801,0957 & 23862,87 \\
& & 7801, & 0 & 274 \\
& & 2725 & & \\
\hline
\end{tabular}

Sumber : SPSS 25, Data Diolah 2019

Berdasarkan uji beda statistik dari perbandingan rata-rata nilai hutang impor menggunakan teknik money market hedging dengan open position menunjukkan Sig. (2tailed) 0,952 . Hal ini berarti tidak ada perbedaan rata-rata nilai hutang impor ketika menggunakan teknik money market hedging dan metode open position, karena nilai signifikansi $(0,05)$ lebih kecil daripada nilai Sig. (2-tailed). Hal ini dapat disebabkan karena peningkatan nilai tukar Dolar AS terhadap Rupiah selama jatuh tempo setiap transaksi tidak signifikan. Nurmalasari (2013) dan Suidarma (2016) mendapatkan hasil penelitian yang sama, perbedaannya terletak di hasil signifikansinya dan penghematan penggunaan money market hedgingnya.

Sedangkan berdasarkan nilai hutang impor yang dihasilkan dari penggunaan teknik money market hedging pada 11 perusahaan menunjukkan nilai yang lebih rendah dibandingkan menggunakan metode open position. Berikut nilai hutang impor perusahaan :
Tabel 5

Nilai Hutang Impor Money Market Hedging dan Open Position

\begin{tabular}{|c|l|}
\hline \multicolumn{1}{|c|}{ Keterangan } & \multicolumn{1}{c|}{ Jumlah } \\
\hline $\begin{array}{l}\text { Money Market } \\
\text { Hedging }\end{array}$ & $\mathrm{Rp}$ \\
\hline \multirow{2}{*}{ Open Position } & $\mathrm{Rp}$ \\
& $45.526 .972 .019 .332,30$ \\
\hline Selisih & $\mathrm{Rp}$ \\
& $775.523 .559 .579 .070,00$ \\
\hline
\end{tabular}

Sumber : Data Diolah, 2019

Dari perbandingan tabel di atas dapat dilihat bahwa terdapat selisih nilai hutang yang harus dibayarkan oleh perusahaan dari tahun 2014-2018 ketika menggunakan teknik money market hedging dan open position. Saat menggunakan teknik money market hedging perusahaan akan membayar sebesar Rp. 44.526.972.019.332,30 sedangkan saat tidak melakukan teknik hedging atau menggunakan metode open position sebesar Rp. 45.302.495.579.070,00. Itu berarti penggunaan money market hedging akan memperoleh penghematan sebesar Rp. 775.523.559.737,65 meskipun menurut uji beda T-test tidak terdapat perbedaan yang signifikan.

\section{Simpulan Dan Saran}

\subsection{Simpulan}

Berdasarkan hasil penelitian yang telah dilakukan, maka dapat diambil kesimpulan sebagai berikut :

a. Tidak ada perbedaan yang signifikan antara pembayaran hutang impor menggunakan forward contract hedging dengan open position dalam meminimalkan pembayaran hutang impor. Hal tersebut terbukti dari nilai signifikansi yang diperoleh lebih kecil dari nilai hitung Sig. (2-tailed), yaitu $0,05<0,988$.

Namun, dengan menggunakan teknik forward contract hedging akan ada penghematan yang diperoleh yaitu sebesar Rp. 196.677.815.083,35 yang artinya akan memberikan keuntungan bagi perusahaan dibandingkan tidak melakukan hedging (open position).

b. Tidak ada perbedaan yang signifikan antara pembayaran hutang impor 
menggunakan money market hedging dengan open position dalam meminimalkan pembayaran hutang impor. Hal tersebut terbukti dari nilai signifikansi yang diperoleh lebih kecil dari nilai hitung Sig. (2-tailed), yaitu $0,05<0,952$.

Namun, dengan menggunakan teknik money market hedging akan ada penghematan yang diperoleh yaitu sebesar Rp. 775.523.559.737,65 yang artinya akan memberikan keuntungan bagi perusahaan dibandingkan tidak melakukan hedging (open position).

\subsection{Saran}

Berdasarkan dari hasil penelitian ini, terdapat beberapa saran yang dapat dipertimbangkan oleh berbagai pihak, antara lain:

a. Bagi investor, akan lebih memahami di perusahaan mana mereka akan berinvestasi jika mengetahui kinerja masing-masing perusahaan khususnya pada kinerja keuangan yang dikelola. Mengelola hutang adalah salah satu alasan para investor berinvestasi.

b. Sebagai perusahaan yang sahamnya terdaftar di BEI, tindakan yang dapat dilakukan untuk mengurangi kerugian selisih kurs yang juga akan meningkatkan laba usahanya adalah dengan menerapkan forward contract hedging dan money market hedging (teknik hedging) atas liabilitas usaha bersih dalam mata uang asingnya.

c. Penggunaan teknik hedging dapat dijadikan alternatif bagi perusahaan untuk melindungi nilai hutang impornya. Berdasarkan hasil penelitian ini, nilai hutang impor yang paling rendah adalah ketika menggunakan teknik money market hedging. Namun, sebelum memutuskan untuk menggunakan hedging, perusahaan sebaiknya mempertimbangkan faktorfaktor yang terlibat dalam penggunaan teknik hedging seperti nilai tukar antara mata uang asing terkait, suku bunga deposito negara-negara terkait, suku bunga pinjaman mata uang asing terkait dan waktu jatuh tempo hutang.

\section{DAFTAR PUSTAKA}

Brigham, E. F., dan Houston, J. F. (2006). Manajemen Keuangan, buku II. Jakarta: Erlangga.
Bank Indonesia. Online. www.bi.go.id (21 April 2019)

Bursa Efek Indonesia. Online. https://www.idx.co.id/data-pasar (16 Januari 2019).

Cheol, S.Eun dan Resnick. (2001). International Financial Management. Singapore: Mc.GrawHill.Inc.

Eiteman, D. K., Stonehill, A. I., dan Moffet, M. H. (2010). Manajemen Keuangan Multinasional. Edisi Kesebelas. Jakarta: Erlangga.

Ekananda, M. (2014). Ekonomi Internasional. Jakarta: Erlangga.

Ghozali, Imam. (2018). Aplikasi Analisis Multivariate Dengan Program IBM SPSS 25. Semarang: Badan Penerbit Universitas Diponegoro.

Gunawan, Itjang D. (2003). Transaksi Derivatif, Hedging dan Pasar Modal. Jakarta: PT Grasindo.

Habibah, Suhariana. (2016). Forward Exchange Contract. Online. http://talentiakirsti.blogspot.com/2016/04/forwa rd-exchange-contract.html. (15 Maret 2019).

Hady, Hamdy. (2016). Manajemen Keuangan Internasional (Edisi 4). Jakarta: Mitra Wacana Media.

Hanafi, Mamduh. (2016). Manajemen Risiko. Edisi 3. Yogyakarta: UPP STIM YKPN.

Hanafi, Mamduh. (2016). Manajemen Keuangan Internasional (Edisi 3). Yogyakarta: BPFEYogyakarta.

Hawa, Ibtihaj. (2015). Perbandingan Penggunaan Open Position dan Teknik Hedging dalam Menilai Rata-Rata Hutang Impor (Studi Pada Perusahaan Manufaktur yang terdaftar di BEI Periode 2011-2013). Online. http://digilib.unila.ac.id/7288/. (30 Desember 2018).

Kuncoro, Mudrajad. (1996). Manajemen Keuangan Internasional: Pengantar Ekonomi dan Bisnis Global. Edisi Ke-1. Yogyakarta: BPFEYogyakarta.

Kuncoro, Mudrajad. (2017). Manajemen Keuangan Internasional: Pengantar Ekonomi dan Bisnis Global. Edisi Ke-3. Yogyakarta: BPFEYogyakarta.

Levi, Maurice D. (2005). International Finance. Edisi ke-empat. Singapore: Mc.Graw-Hill.Inc.

Madura, Jeff. (2000). Manajemen Keuangan Internasional Jilid 1. Edisi Ke 4. Jakarta: Erlangga. 
Mitariani, Ni Wayan E., Sedana I. B. P., \& Badjra I. B. (2013). Analisis Perbandingan Penggunaan Hedging Antara Forward Contract Dengan Currency Swap Untuk Meminimasi Risiko Foreign Exchange. Manajemen, Strategi Bisnis Dan Kewirausahaan. Online. Vol. 7 No. 1, Hal : $1-7$.

https://ojs.unud.ac.id/index.php/jmbk/article/vie w/6057/4554. (18 November 2018).

Mustafidah, Hidayatul. (2017). Perbandingan Forward Contract Hedging dan Open Position dalam Meminimalkan Hutang Impor (Studi Pada Perusahaan Manufaktur yang Terdaftar di ISSI 2012-2015. Online. http://digilib.uinsuka.ac.id/26407/. (03 Desember 2018).

Nur, Mushlihatun. (2013). Analisis Kebijakan Lindung Nilai dan Pengaruhnya Terhadap Nilai Perusahaan: Studi Empiris Pada Bursa Efek Indonesia. Online. https://repository.ipb.ac.id/jspui/bitstream/1234 56789/63116/1/2013. (19 November 2018).

Nurmalasari, Made Ratih \& Purnawati, Ni Ketut. (2013). Perbandingan Penggunaan Teknik Hedging Dengan Open Position Dalam Meminimalisasi Nilai Hutang Impor. E-Jurnal Manajemen. Online. https://www.neliti.com/publications/254654/. (19 November 2018).

Sugiyono. (2017). Metode Penelitian Bisnis. Edisi Ke3. Bandung: Alfabeta.

Suidarma, I. Made., Nidiacitra,, \& Diatmika. (2016). "Perbandingan Penggunaan Hedging Dan Open Position Sebagai Manajemen Risiko Keuangan Atas Transaction". Manajemen Ilmiah Untab. Online. Vol. 14 (2), 10 Hal. http://www.universitastabanan.ac.id/journals/do wnload/perbandingan-penggunaan-hedgingdan-open-position. (14 November 2018).

Suliyanto. (2018). Metode Penelitian Bisnis Untuk Skripsi, Tesis dan Disertasi. Edisi 1. Yogyakarta: CV. Andi Offset. 